Nefzger, M. D., and Chalmers, T. C. (1963). Amer. f. Med., 35, 299.

Ramalingaswami, V., Wig, K. L., and Sama, S. K. (1962). Arch. intern. Med., 110, 350 .

Roholm, K., and Iversen, P. (1939). Acta path. microbiol. scand., 16, 427.

Sherlock, S. (1948). Lancet, 1, 817.

_ and Walshe, V. (1946). Ibid., 2, 482.
Sidhu, A. S., and Nair, S. S. (1957). Indian f. med. Res., 45, Suppl., p. 31 .

Viswanathan, R. (1957). Ibid., 45, Suppl., p. 1.

Volwiler, W., and Elliott, J. A. (1948). Gastroenterology, 10, 349.

Wootton, I. D: P. (1964): Micro-Analysis in Medical Biochemistry, 4th ed., p. 79. Churchill, London.

Wyllie, W. G., and Edmunds, M. E. (1949). Lancet, 2, 553.

Zieve, L., Hill, E., Nesbitt, S., and Zieve, B. (1953). Gastroenterology, $25,495$.

\title{
Early Dietary Management of Sugar Intolerance in Infancy
}

\author{
BARBARA E. CLAYTON, ${ }^{*}$ M.D., PH.D., M.R.C.P., M.C.PATH.; A. B. ARTHUR, ${ }^{*}$ M.B., M.R.C.P.ED., D.C.H. \\ DOROTHY E. M. FRANCIS,* S.R.D.
}

Brit. med. F., 1966, 2, 679-682

Infants who show intolerance of one or more sugars are being increasingly recognized. Though such a condition may be congenital, sugar intolerances secondary to a variety of enteric conditions present a far greater problem-for example, secondary to coeliac disease (Plotkin and Isselbacher, 1964), enteric infection (Careddu, Giovannini and Cevini, 1963), giardiasis (Durand, 1964), sprue (Santini, Aviles, and Sheehy, 1960), kwashiorkor (Bowie, Brinkman, and Hansen, 1965), and cystic fibrosis (Cozzetto, 1963).

As early as 1911 Finkelstein and Meyer advised the reduction of milk sugar in the dietary treatment of infants with gastrointestinal disturbances. Intolerance to carbohydrates, both temporarily following acute diarrhoea and persistently associated with chronic intestinal disease, was described by Howland (1921), who advised carbohydrate restriction for infants with either severe or prolonged diarrhoea.

Successful treatment by the removal of the offending sugars from the diet has recently been described by a number of workers-for example, Anderson, Kerry, and Townley (1965), Lifshitz, Klotz, and Holman (1965), Burke, Kerry, and Anderson, (1965), and Arthur, Clayton, Cottom, Seakins, and Platt (1966).

The purpose of this paper is to describe the practical details in the management of infants requiring diets free of certain sugars.

\section{Preparations Used Instead of Cow's Milk or Breast Milk}

The following preparations have been used satisfactorily:

1. Galactomin No. 17 (Trufood): a low-lactose, full-fat food with liquid glucose as the carbohydrate. (Low-lactose milk food made by Cow and Gate is similar.)

2. Reduced-fat Galactomin (manufactured for our use by Trufood): a low-lactose, reduced-fat food with liquid glucose as the carbohydrate. $\dagger$

3. Reduced-fat, fructose-formula Galactomin (manufactured for our use by Trufood): a low-lactose, low-fat food with fructose as the carbohydrate.

4. Lactase-treated breast milk: prepared in the diet kitchen of the hospital. Lactase splits lactose to glucose and galactose.

The amount of lactose remaining in these preparations is insignificant, and they may be considered "lactose-free."

- Hospital for Sick Children, Great Ormond Street, London.

+ Reduced-fat Galactomin and reduced-fat, fructose-formula Galactomin are now available commercially from Trufood Ltd.
Details of preparations 1,2 , and 3 are given in Table $I$. Lactase-treated breast milk is made in the following manner, the procedure being an adaptation of that described by the Royal Netherlands Fermentation Industries Ltd. (personal communication, 1963). 1 g. lactase (T. J. Sas \& Son, Ltd.) is added, as a powder, to each litre of breast milk. The mixture is incubated in a water-bath at $35^{\circ} \mathrm{C}$. for two hours and is shaken occasionally. A further $1 \mathrm{~g}$. of lactase per litre of milk is then added and the incubation continued similarly for a further two hours. A sample is then removed for culture. The mixture is brought to the boil, and then boiled for 20 minutes. A further sample is taken for culture. The milk is then deep-frozen at $-15^{\circ} \mathrm{C}$.

TABLB I.-Composition of Synthetic Milks

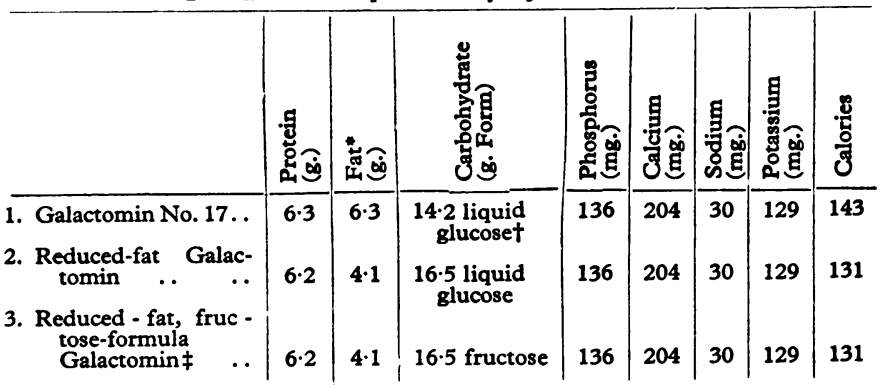

All quantities are in $\mathrm{g}$. or $\mathrm{mg}$./oz. dry powder, which is normally reconstituted

as a 1 -in-8 dilution.
$*$ Fat $=$ Blend of unhydrogenated coconut and maize oils.

t Liquid glucose is a mixture of dextrin, maltose, and dextrose.

This milk is manufactured as a dry mix, and is not spray-dried.

It has been our experience that in secondary lactose intolerance there is generally intolerance of sucrose too. As the infant is often too ill for a series of diagnostic tests, we remove sucrose routinely as well as lactose from the diet. We therefore do not usually use Velactin (Wander) or Nutramigen (Mead Johnson), as both preparations contain added sucrose, though only a trace of lactose.

Since infants are particularly susceptible to deprivation of vitamins (Mann, Wilson, and Clayton, 1965), it is essential that adequate supplements be given with the preparations listed in Table I and with lactase-treated breast milk. A recommended supplement is three tablets of Ketovite plus $5 \mathrm{ml}$. of Ketovite supplement liquid (Paines \& Byrne) daily. These preparations are lactose- and sucrose-free. Supplements containing vitamins $\mathrm{A}, \mathrm{D}, \mathrm{C}$, and the commoner ones of group $\mathrm{B}$ are not adequate. 
Preparations 1, 2, and 3 (Table I) are deficient in a number of elements. In the rare patient who has remained on one of these preparations without any other foods for many months we have given a supplement. When the preparation has been given for a short time we have not always included an element supplement, though it is now our custom to do so. The daily supplement is a modification of that described by Westall (1963), and consists of: ferrous sulphate $20 \mathrm{mg}$., copper sulphate $2 \mathrm{mg}$., zinc chloride $2 \mathrm{mg}$., manganese sulphate $2 \mathrm{mg}$., potassium iodide $80 \mu \mathrm{g}$., potash alum $30 \mu \mathrm{g}$., cobalt sulphate $30 \mu \mathrm{g}$., sodium molybdate $30 \mu \mathrm{g}$. These are made up to $1 \mathrm{~g}$. with sodium chloride.

A tablet containing vitamins and trace elements manufactured by Trufood has not generally been used, as it contains sucrose.

The unwitting administration of one or more offending sugars to children on a diet is common-for example, ascorbic acid is usually made up in lactose, and many antibiotics and sedatives are made up in syrups of cane sugar. It can take a surprising amount of searching to track down such sources in children who are failing to response to an apparently suitable diet.

It has been particularly helpful to have low-fat preparations available. When the infant begins to thrive the fat intake can be increased gradually by adding Prosparol (Duncan Flockhart) to the feeds. Prosparol is an emulsion of equal parts of arachis oil and water, and has a reasonably pleasant flavour.

If extra sugar is required to increase the infant's calorie intake, glucose should be added to preparations 1 and 2 and fructose to preparation 3 .

If one of the preparations described is not immediately available the following mixture is suitable, being lactose- and sucrosefree : $4 \frac{1}{2}$ whole eggs, fructose (or glucose) $2 \frac{1}{2} \mathrm{oz}$. (78 g.), vitamins (3 Ketovite tablets $+5 \mathrm{ml}$. Ketovite supplement liquid), the complete element-mixture described by Westall (1963), water to $36 \mathrm{oz}$. (1,022 ml.).

The eggs, sugar, and water should be cooked in a double saucepan and the vitamins and element-mixture added after cooking. This recipe gives the equivalent of $36 \mathrm{oz}$. $(1,022 \mathrm{ml}$.) of cows' milk.

\section{Some Illustrative Case Reports}

The cases described and the preparations used successfully are summarized in Table II.

\begin{tabular}{|c|c|c|}
\hline $\begin{array}{l}\text { Case } \\
\text { No. }\end{array}$ & Cause of Sugar Intolerance & $\begin{array}{l}\text { Dietary Preparation on which } \\
\text { Infant Thrived }\end{array}$ \\
\hline 1 & $\begin{array}{l}\text { Secondary to chronic enteritis due to } \\
\text { E. coli } 0127\end{array}$ & Reduced-fat Galactomin \\
\hline $\begin{array}{l}2 \\
3\end{array}$ & Presumed secondary to gastro-enteritis & $"$ \\
\hline 4 & 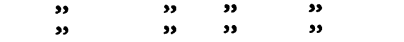 & Galactomin No. 17" \\
\hline $\begin{array}{l}5 \\
6\end{array}$ & $\begin{array}{l}\text { Severe enteritis" of unknown" cause ; } \\
\text { Candida albicans later isolated from }\end{array}$ & $\begin{array}{l}\text { Lactase-treated breast milk ; then } \\
\text { reduced-fat Galactomin }\end{array}$ \\
\hline 7 & $\begin{array}{l}\text { Secondary to acrodermatitis entero- } \\
\text { pathica }\end{array}$ & $\begin{array}{l}\text { Reduced-fat, fructose-formula } \\
\text { Galactomin }\end{array}$ \\
\hline
\end{tabular}

\section{Case 1}

This patient had secondary disaccharide intolerance following gastro-enteritis due to Escherichia coli 0127 . He weighed $3.6 \mathrm{~kg}$. after a normal full-term delivery. At the age of 5 weeks he developed green watery foul-smelling stools of consistently acid $\mathrm{pH}$ from which pathogenic $E$. coli 0127 was cultured on several occasions. He became dehydrated and malnourished, his weight at 6 weeks of age being $227 \mathrm{~g}$. below his birth weight. He had a persistent lactosuria, and this, together with acid diarrhoea, was suggestive of disaccharide intolerance, presumably secondary to the enteric infection.

He was treated with a full-fat lactose-free milk (low-lactose milk food, Cow and Gate) and antibiotics, with only minimal change, but there was rapid clinical improvement accompanied by gain in weight on changing him to reduced-fat Galactomin. By the age of 6 months he weighed $7.8 \mathrm{~kg}$. despite a recurrence of infection with E. coli 0127 . He was then able to tolerate galactomin No. 17 with its full-fat content but could not tolerate added lactose.

\section{Case 2}

This patient was found in a garbage-can in Dar-es-Salaam when about 7 days old and weighing $2.4 \mathrm{~kg}$. Five days later she became jaundiced, dehydrated, and acidotic, and required intravenous fluids. No clear diagnosis was made. Various feeding regimens were tried, but recurrent acid diarrhoea, vomiting, and dehydration followed all attempts to feed her with milks of greater than quarter strength. At 3 weeks of age reducing substances (non-glucose) were noted in the urine, but a trial of Nutramigen brought only temporary relief. She was transferred to the Hospital for Sick Children when aged about $2 \frac{1}{2}$ months.

After initial investigation to exclude an enteric infection she was fed with reduced-fat Galactomin and made an immediate and striking response, with a weight gain of $600 \mathrm{~g}$. in 14 days. She was discharged aged 15 weeks weighing $3.6 \mathrm{~kg}$.

Further progress has been satisfactory, but follow-up at the age of 14 months showed that she still was unable to tolerate a full-fat synthetic food (Galactomin No. 17) or the addition of much sucrose in her diet. She was being maintained on reduced-fat Galactomin, baby rice, liver, steak, chicken, tomatoes, and eggs. $\mathrm{Her}$ intolerance was presumed to be secondary to gastro-enteritis.

\section{Case 3}

This patient was born after 43 weeks' gestation, weighing 3.2 $\mathrm{kg}$. He was artificially fed, and occasional vomiting was noted in the neonatal period. He began to have loose stools at the age of 3 weeks, and by 9 weeks they had become frequent and watery. During the 12 days prior to admission at the age of 10 weeks he lost $340 \mathrm{~g}$. On admission he was dehydrated. No enteric pathogens were isolated from the stools, but his urine contained excessive amounts of lactose and sucrose.

As the findings were suggestive of disaccharide intolerance, treatment was begun with reduced-fat Galactomin. The diarrhoea stopped and he began to gain. After seven weeks on this preparation he was gradually changed to a normal milk diet. The precise cause of his temporary sugar intolerance was not determined, but a viral gastro-enteritis was thought most likely.

\section{Case 4}

This patient thrived until 4 weeks of age, after normal full-term delivery with a birth weight of $3.8 \mathrm{~kg}$. He then developed diarrhoea, and four weeks later started to vomit. During this time he received full-cream national dried milk, and began mixed feeding at 2 months of age.

When admitted at the age of 14 weeks he was thin and wasted, with a distended abdomen. Stool cultures were negative. No clear diagnosis was made. A glucose-tolerance test showed a maximum rise of only $20 \mathrm{mg}$. of blood sugar per $100 \mathrm{ml}$. A barium-meal examination revealed coarsening of the mucosal folds in the jejunum. A disaccharide loading test suggested impaired utilization of lactose and sucrose, although stool $\mathrm{pH}$ remained about 6 . In view of suspected disaccharide intolerance (cause unknown, but a previous enteric infection is possible) he was fed on Galactomin No. 17. He improved rapidly, gaining $500 \mathrm{~g}$. in 18 days, with a return to normal bowel habit.

\section{Case 5}

This patient was born after 39 weeks' gestation, weighing $2.7 \mathrm{~kg}$. He thrived initially despite a cleft palate and hare-lip, the latter being successfully repaired at 15 days. Vomiting, diarrhoea, and abdominal distension developed at 22 days, causing severe dehydration which necessitated intravenous therapy. No enteric pathogens were isolated from his stools at this time. After this he remained 
well until aged 11 weeks, when abdominal distension recurred accompanied by the passage of loose bulky stools.

On admission to hospital at 12 weeks he weighed $3.4 \mathrm{~kg}$. $\mathrm{He}$ was alert but undernourished, with no abnormal physical signs other than moderate abdominal distension together with a cleft palate and a repaired hare-lip. Investigations showed lactosuria, mild sucrosuria, and lactose in the stools. Various carbohydrate-tolerance tests showed impaired absorption but no change in stool $\mathrm{pH}$ or transit time, and no particular sugar was significantly incriminated. Stool cultures were negative. Although the investigations were not conclusive, disaccharide intolerance, possibly secondary to previous gastro-enteritis, was suspected and treatment was begun with a lowlactose, low-sucrose diet. He was unable to tolerate Galactomin weight $4.5 \mathrm{~kg}$., and remained well until $2 \frac{1}{2}$ months of age. Thereafter she gradually developed a rash, and then had occasional vomiting and loose foul stools. At 7 months acrodermatitis enteropathica was diagnosed, and treatment with di-iodohydroxyquinoline was begun.

She was marasmic with a widespread rash and severe diarrhoea when admitted to the Hospital for Sick Children. On a diet of breast milk supplemented with dextrose she had gross lactosuria, and her loose stools contained large amounts of lactose, galactose, and glucose. No enteric pathogens could be isolated.

In view of the apparent disaccharide intolerance, and as she was desperately ill, she was fed on a mixture of Casilan, fructose, and Prosparol, and then on reduced-fat, fructose-formula Galactomin

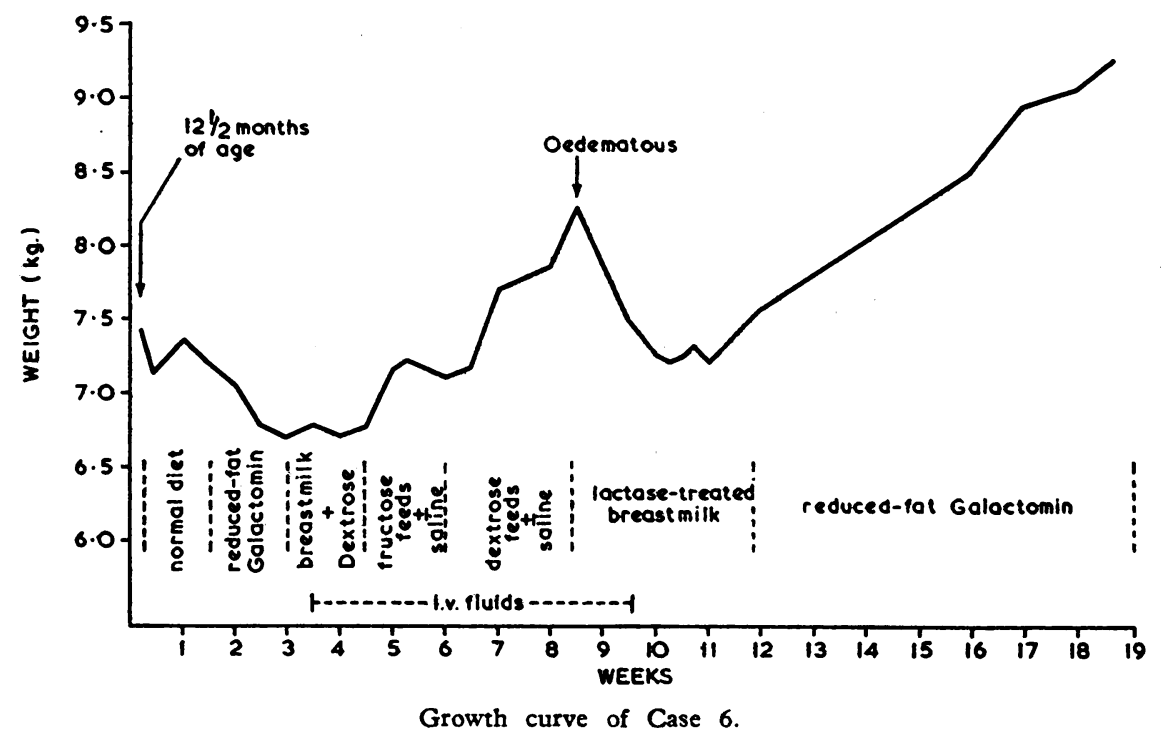

No. 17, but improved rapidly on changing to reduced-fat Galactomin and gained $1.4 \mathrm{~kg}$. in the next seven weeks. Although doing well, he was still unable to tolerate the full-fat preparation at the age of 7 months.

\section{Case 6}

This patient had severe enteritis with septicaemia and secondary sugar intolerance. After a normal full-term delivery, birth weight $3.3 \mathrm{~kg}$., he made fair progress apart from a vomiting episode at 3 months, and by 10 months weighed $8.7 \mathrm{~kg}$. He then began passing up to seven watery stools daily, and had episodes of vomiting with anorexia. He lost $1 \mathrm{~kg}$. in weight during the next 10 weeks.

On admission at $12 \frac{1}{2}$ months he was dehydrated and had a distended abdomen, poor muscle tone, and anaemia. Investigations showed a low serum folate, and lactosuria and sucrosuria in random urines. After a lactose-sucrose load he also had lactosuria and sucrosuria, and large amounts of fructose in his stool.

Feeding with reduced-fat Galactomin was begun, but he became increasingly dehydrated. For the next six weeks he was maintained on intravenous fluid with occasional oral fluids (see Chart). During this period he had first a staphylococcal septicaemia, which was treated with intravenous methicillin and chloramphenicol, and then Candida albicans was isolated from his stools and blood. His condition improved after treatment with Amphotericin B, and oral feeding was begun again, this time with quarter, then half, then three-quarter strength lactase-treated breast milk. Diarrhoea did not recur, he began to gain weight, and aftrr three and a half weeks he was successfully changed to reduced-fat Galactomin.

The cause of his extremely severe enteri symptoms was not determined, but three months later he was pi sgressing well on a mixed diet free of lactose, sucrose, and gluten.

\section{Case 7}

This patient had sugar intolerance secondary to acrodermatitis enteropathica. She was born at full-time by caesarean section, birth
On this she showed some improvement. On changing to threequarter-strength reduced-fat Galactomin there was a partial relapse, but some improvement occurred when only half-strength was used As she appeared to be worse when the diet contained glucose, she was changed back to reduced-fat, fructose-formula Galactomin Thereafter she made excellent progress, and gained $1.4 \mathrm{~kg}$. in the next eight weeks.

\section{Discussion}

Infants with secondary sugar intolerances have usually been so ill when admitted to hospital that it has not been feasible to carry out a series of sugar-loading tests in order to reach a firm diagnosis. Rather, the diagnosis has often been made in retrospect after observing the infant's response to removal of one or more sugars from the diet.

To the best of our knowledge the milk substitutes described in this paper are satisfactory foods for infants, but it is absolutely essential that the complete vitamin supplement should be given. It is advisable to give the element mixture too, particularly if the infant is to receive the synthetic preparation for a long time.

Reduced-fat Galactomin appears to be particularly satisfactory for the treatment of lactose and sucrose intolerance in infancy, and if the condition is suspected there would seem to be no harm in giving the preparation a trial.

We have used lactase-treated breast milk in a few patients only, but think it is worth a trial in a desperately ill infant in whom lactose intolerance is suspected. The preparation would probably be improved if a satisfactory method for removing galactose from it could be found.

\section{Summary}

Some practical details in the dietary management of infants with secondary sugar intolerances are described. Milk sub- 
stitutes have been used satisfactorily; the necessity for giving complete vitamin supplements is stressed.

We thank the consulting physicians at the Hospital for Sick Children for permission to study patients under their care. It is a great pleasure to acknowledge the close collaboration of $\mathrm{Mr}$. J. V. Hyde, of Trufood Ltd., throughout this work. We are indebted to Mr. R. Ersser for technical assistance. We gratefully acknowledge financial support from the Joint Research Board of the Hospital for Sick Children and Institute of Child Health.

\section{REFERENCES}

Anderson, C. M., Kerry, K. R., and Townley, R. R. W. (1965). Arch. Dis. Childh., 40, 1.

Arthur, A. B. Clayton, B. E., Cottom, D. G., Seakins, J. W. T., and Platt, J. W. (1966). Lancet, 1, 172.
Bowie, M. D., Brinkman, G. L., and Hansen, J. D. L. (1965). F. Pediat., 66, 1083 .

Burke, V., Kerry, K. R., and Anderson, C. M. (1965). Aust. paediat. 7., $1,147$.

Careddu, P., Giovannini, M., and Cevini, G. (1963). Helv. paediat. Acta, 18, 97 .

Cozzetto, F. J. (1963). Pediatrics, 32, 228.

Durand, P. (1964). In Disorders Due to Intestinal Defective Carbokydrate Digestion and Absorption, edited by P. Durand. Pensiero Scientifico, Rome.

Finkelstein, H., and Meyer, L. F. (1911). Münch. med. Wschr., 58, 340.

Howland, J. (1921). Trans. Amer. pediat. Soc., 33, 11.

Lifshitz, F., Klotz, A. P., and Holman, G. H. (1965). Amer. 7. dig. Dis., io, 47.

Mann, T. P., Wilson, K. M., and Clayton, B. E. (1965). Arch. Dis. Childh., 40, 364.

Plotkin, G. R., and Isselbacher, K. J. (1964). New Engl. F. Med., 271, 1033.

Santini, R., Aviles, J., and Sheehy, T. W. (1960). Amer. F. dig. Dis., 5, Westall, R. G. (1963). Arch. Dis. Childh., 38, 485.

\title{
Ehlers-Danlos Syndrome: Associated with Prematurity and Premature Rupture of Foetal Membranes; Possible Increase in Incidence
}

\author{
A. P. BARABAS, ${ }^{*}$ M.B., F.R.C.S.
}

Brit. med. F., 1966, 2, 682-684

The Ehlers-Danlos syndrome is an inherited disorder of the connective tissue. It belongs to the same group of disorders as the Marfan syndrome, osteogenesis imperfecta, and pseudooxanthoma elasticum (McKusick, 1960). The main clinical features are: (1) fragility of the skin and of the dermal bloodvessels, (2) characteristic " papyraceous" scars, (3) hyperextensible skin, and (4) hypermobile joints. The basic defect is believed to lie in the organization of collagen into a stable collagen "wickerwork" (Jansen, 1955).

In this article evidence is presented that most babies with Ehlers-Danlos syndrome are born prematurely after premature rupture of foetal membranes. In all patients the fragility of foetal membranes (as shown by the degree of prematurity) is well correlated with the fragility of skin (as shown by the amount of skin-scarring). Finally, it is argued that in countries with gond antenatal and premature-infant care an increase in the number of surviving Ehlers-Danlos patients is likely.

These observations were made on a group of 39 affected individuals-the largest series of Ehlers-Danlos patients so far recorded. The syndrome is generally regarded as extremely rare, but this is due partly to a failure to recognize less obvious cases.

\section{Material and Diagnosis}

Twenty patients were personally examined, and in the remaining 19 detailed hospital records were available. The diagnosis of Ehlers-Danlos syndrome was made on clinical signs, since there are no specific laboratory, radiological, or histological findings. A biopsy of the skin was carried out in half of the patients: in every case microscopical appearances were compatible with the diagnosis of Ehlers-Danlos syndrome.

All patients reported here had a tendency to excessive bruising, laceration of the skin after minor trauma, and varying degrees of skin hyperextensibility and joint hypermobility. In every patient characteristic thin hyperpigmented scars, especi-

* Surgical Registrar, the Postgraduate Medical School of London and Hammersmith Hospital, London. ally over the knees, shins, and forehead, were found (Figs. 1 and 2).

Prematurity was defined as a birthweight of less than $5 \frac{1}{2} \mathrm{lb}$. (2,500 g.) (British Medical fournal, 1961). Rupture of the foetal membranes is defined as "premature" where this occurs before the onset of labour.

\section{Results}

Prematurity.-In 18 of the 39 patients studied details of the circumstances of birth were known ; 14 were born prematurely and in four the birth-weight exceeded $5 \frac{1}{2} \mathrm{lb}$. Premature babies were born between the 32nd and 35th weeks of pregnancy. They were premature, therefore, not only by their birth-weight but by dates as well. Three of the four nonpremature affected babies were born in the same family (Fig. 3, Cases 16, 17, and 18).

Premature Rupture of Foetal Membranes.-In 13 of the 14 premature births labour definitely started after rupture of foetal membranes. Such occurred also in two out of the four nonpremature births. The time of rupture was not recorded in the remaining three births. However, in no birth of an EhlersDanlos baby could premature rupture of the membranes definitely be excluded.

Correlation between Birth-weight and Clinical Picture.-The present series is too small for any definite statement to be made on this correlation. However, among all examined patients the one case (Case 4) with the lowest birth-weight, $3 \frac{1}{2} \mathrm{lb}$. (1,590 g.), had the most severe scarring and another patient (Case 8) with the highest birth-weight, $7 \frac{1}{2} \mathrm{lb}$. $(3,400 \mathrm{~g}$.), had the least scarring of the skin (Figs. 1 and 2). Also, in every patient between these two extremes the birth-weight and amount of scarring seemed to be well correlated.

Unaffected Members of Ehlers-Danlos Families.-In the one case where a mother with clinical signs of Ehlers-Danlos syndrome (Fig. 3, Case 9) gave birth to a normal child, and the circumstance of birth was known, the child was not premature and the foetal membranes ruptured in the second stage of 